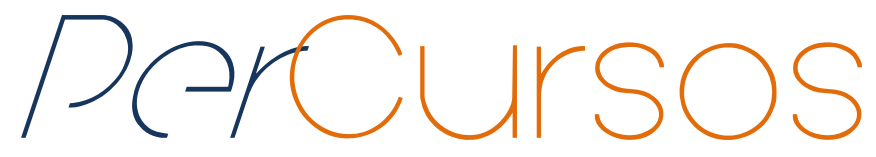

\title{
Seridó Potiguar: apontamentos históricos e socioeconômicos para o estudo da atual dinâmica urbano-regional
}

\section{Resumo}

Entendendo a região como a fragmentação de um todo territorial, um espaço construído historicamente, sobretudo por meio das instâncias econômica, política e cultural, e particularizado por sua fisiografia e pela identidade de sua sociedade, estudamos o Seridó Potiguar como região identificada, ou seja, como espaço vivido historicamente por significados e signos e construído conforme interesses políticos. Assim, por meio de apontamentos históricos e de análises de dados secundários, apreendemos a geografia histórica (formação e produção do espaço) do Seridó, chegando até sua atual dinâmica urbano-regional, particularizada por um processo de reestruturação econômica que tem como importante fundamento as tradições culturais do espaço.

Palavras-chave: Seridó Potiguar. Formação e produção do espaço. Dinâmica urbano-regional.

\section{Diego Salomão Candido de Oliveira Salvador}

Doutor em Geografia pela

Universidade Estadual de Campinas - UNICAMP. Professor de Programas de Pós-Graduação em Geografia da Univ. Federal do Rio Grande do Norte - UFRN.

$$
\text { Brasil }
$$

diegosalomao84@hotmail.com

\section{Marluce Silvino}

Doutoranda em Geografia pela Univ. Federal do Ceará - UFC. Brasil

marluce_silvino@yahoo.com.br

\section{Eulália Jéssica Medeiros Silva Mestranda em Geografia pela Universidade Federal do Rio Grande do Norte - UFRN. Brasil jessmedeiros@@hotmail.com}

\footnotetext{
Para citar este artigo:

SALVADOR, Diego Salomão Candido de Oliveira; SILVINO, Marluce; SILVA, Eulália Jéssica Medeiros. Seridó Potiguar: apontamentos históricos e socioeconômicos para o estudo da atual dinâmica urbanoregional. Revista PerCursos, Florianópolis, v. 20, n.43, p. 120 - 142, maio/ago. 2019.
} 


\title{
Seridó Potiguar: historical and socio-economic approaches for the study of current urban-regional dynamics
}

\begin{abstract}
Understanding the region as the fragmentation of a territorial whole, being a space historically constructed through, above all, the economic, political and cultural instances and particularized by its physiography and the identity of its society, we studied Seridó Potiguar as an identified Region, that is to say, a space lived historically by meanings and signs and constructed according to political interests. Thus, through historical approaches and analysis of secondary data, we learn the historical geography (formation and production of space) of Seridó, reaching its current urban-regional dynamics, particularized by a process of economic restructuring based on the cultural traditions of space.
\end{abstract}

Keywords: Seridó Potiguar. Formation and production of space. Urban-regional dynamics. 


\section{Introdução}

O Seridó Potiguar (mapa 1) é um espaço de significados, particularizado por sua

fisiografia, sua sociedade e suas mercadorias no contexto do território do Rio Grande do Norte.

Mapa 1 - Localização do Rio Grande do Norte no Brasil e do Seridó Potiguar nesse estado da federação

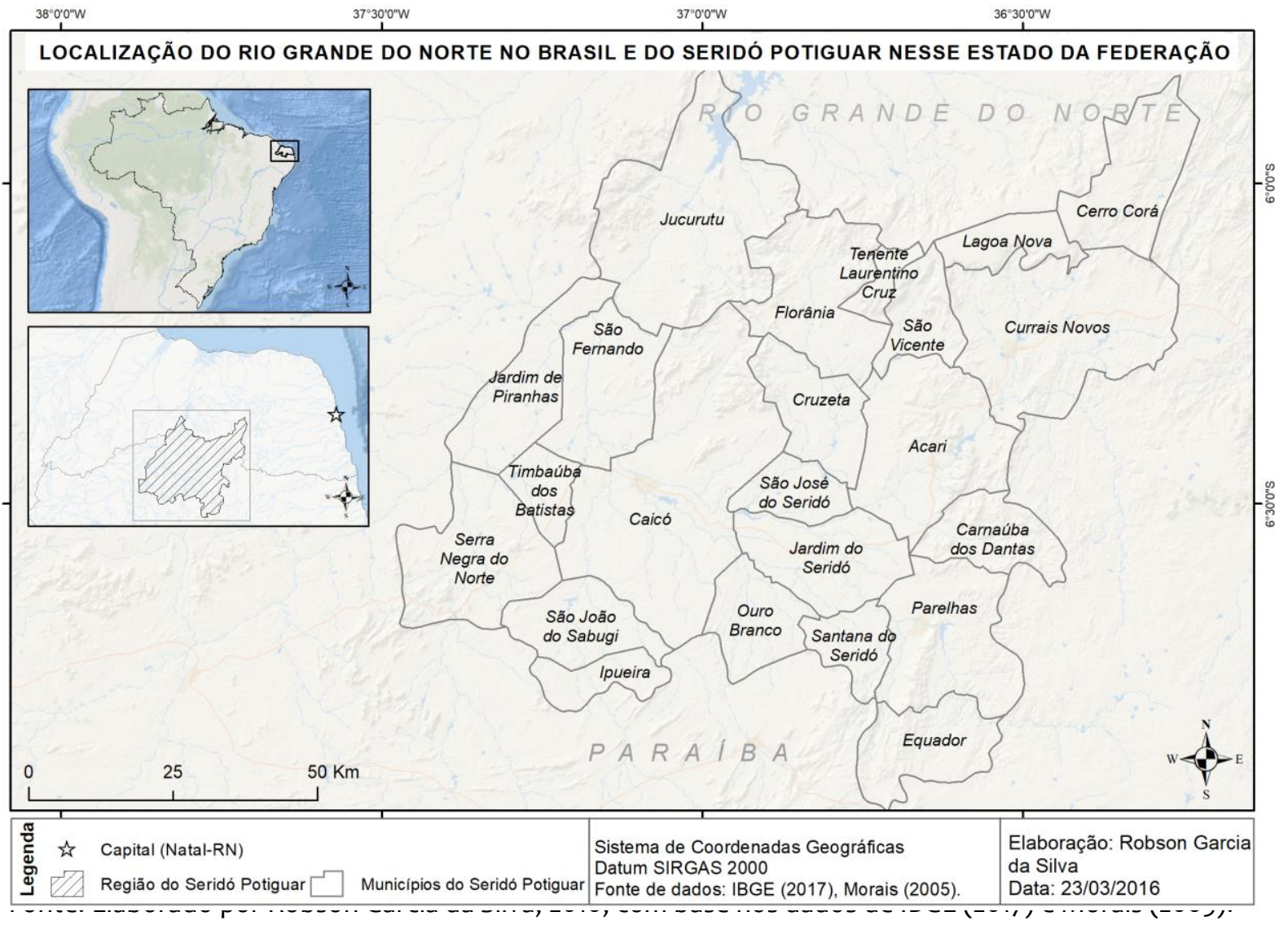

Conforme Morais (2005, p. 23), dados e reflexões históricas indicam que o termo "Seridó" - no sentido da geografia física da região - significa "pouca folhagem" e/ou “pouca sombra", remetendo ao clima semiárido e à xerofilia que caracterizam o espaço. No que concerne à religiosidade da sociedade, o termo "Seridó" decorre do hebraico “Sarid”, que significa “aqui Deus gostou de morar” e/ou “sobrevivente Dele (Deus)”. 
A religiosidade católica foi fundamental para a delimitação geográfica do Seridó como região norte-rio-grandense. A “cartografia da fé seridoense" foi construída historicamente, no processo de formação e produção do espaço, sendo confirmada em 1940, com a criação da Diocese de Caicó considerando os limites da Região do Seridó Potiguar. Esta é constituída, atualmente, por 23 municípios (mapa 1), decorrentes de Caicó, criado em 1788, sediando a então Freguesia da Gloriosa Senhora Sant'Ana do Seridó. Tenente Laurentino Cruz foi o último município dessa cartografia secular, sendo desmembrado de Florânia em 1993.

Macêdo (2000, p. 5) destaca que, no território potiguar, o Seridó é a única região com identidade bem definida. A região dá origem à designação do seu povo - seridoense; “[...] nenhuma outra região do estado tem nome próprio para seus habitantes". 0 significado identitário da Região do Seridó é explicado por Morais (2005, p. 27):

no Rio Grande do Norte, o termo Seridó tornou-se muito mais que a designação de um dado espaço, tornou-se referencial de uma identidade espacial com forte conteúdo histórico-cultural. Neste sentido, a região se configura a partir da evocação de uma certa personalidade, tecida no enredo de sua trajetória de formação, estruturação e reestruturação. A designação de seridoenses para os habitantes do lugar se manifesta tanto entre aqueles que assim se reconhecem, como entre os outros que assim os reconhecem.

Estudando a história do regionalismo seridoense, Macêdo ([2005] 2012) defende que essa região é obra dos interesses de sua elite, isto é, foi criada pelo discurso de seus agentes hegemônicos e é acreditada por seu povo. A criação foi iniciada no século XVIII, quando, sob a primazia econômica da pecuária, evidencia-se o discurso regionalista do Seridó como "espaço da provação e da promissão", sublinhando-se as severas características fisiográficas do espaço, a fé inabalável em Sant'Ana e a força e resistência do homem sertanejo.

Em fins do século XIX e na primeira metade do século $X X$, esse discurso frisava as riquezas geradas com a cotonicultura e a mineração direcionadas à exportação e, assim, a capacidade de o seridoense superar as adversidades da geografia física de seu espaço. 
Hoje, com o processo de reestruturação da economia do Seridó Potiguar, a região é identificada por suas tradições e seus produtos feitos com a máxima qualidade. $\mathrm{O}$ seridoense é significado por sua receptividade com os outros povos e pela qualidade das mercadorias que produz.

Desse modo, partimos da perspectiva da formação socioespacial (SANTOS, 1979), que remete à importância da noção de formação social para os estudos geográficos, tendo em vista o espaço ser um fato histórico, cuja compreensão tem como necessidade a atenção para a história da sociedade que o constrói. Outrossim, frisamos que não há história que possa ser escrita fora do espaço e não há sociedade a-espacial. Assim, com essa perspectiva e corroborando Morais (2005), entendemos a região como a fragmentação de um todo territorial, um espaço construído historicamente, sobretudo por meio das instâncias econômica, política e cultural, e particularizado por sua fisiografia e pela identidade de sua sociedade.

Todavia, a região não é somente um espaço de vivências históricas; é também um espaço de interesses políticos. Por isso, conforme Castro (1992), apreendemos a região como a forma de um discurso (conteúdo) regionalista, um espaço social, historicamente produzido e significado. Outrossim, seguindo Albuquerque Júnior (1994), compreendemos o regionalismo como repertório cultural pertinente a estratégias de poder, ou, em outras palavras, como uma estratégia de convencimento.

Com esse lastro, estudamos o Seridó Potiguar como região identificada, ou seja, como espaço vivido historicamente por significados e signos. De modo geral, apreendemos a geografia histórica do Seridó chegando até sua atual dinâmica urbanoregional, particularizada por um processo de reestruturação econômica que tem como importante fundamento as tradições culturais do espaço.

\section{Geografia histórica do Seridó Potiguar}

Abordamos a geografia histórica da Região do Seridó Potiguar com o embasamento das obras de Macêdo ([2005] 2012) e Morais (2005). Destarte, consideramos que o espaço do Seridó Potiguar foi formado no período do Brasil Colônia 
(1530-1815) e no do Brasil Império (1822-1889). Mais precisamente, a ocupação efetiva desse espaço ocorreu a partir do século XVII, quando, no contexto da Guerra dos Bárbaros (1650-1720), os indígenas que habitavam o Seridó foram colonizados pelos portugueses.

Advindos, principalmente, de Pernambuco e da Paraíba, os colonizadores do Seridó ocuparam o espaço sertanejo por meio do criatório do gado. Considerando aspectos fisiográficos, a Coroa Portuguesa designou, para o litoral da Colônia, a especialização da produção canavieira e, para o interior, o desencadeamento da pecuária.

Não era pertinente que o gado fosse criado, de modo denso, no litoral, pois isso prejudicava os intentos da monocultura canavieira. Destarte, cabia ao sertão o desenvolvimento da pecuária, como atividade associada à canavieira, por ofertar animais utilizados como força motriz nos engenhos e carne para alimentar os colonos do litoral.

Assim, nas proximidades de rios, foram sendo instalados sítios e, posteriormente, fazendas de gado. Macêdo ([2005] 2012, p. 41) afirma que o criador ou o vaqueiro iniciavam suas atividades com uma "semente de gado - um touro e três vacas", configurando, aos poucos, o Seridó como espaço da pecuária bovina.

A formação desse espaço não se deveu apenas à pecuária. A religião católica influenciou, desde os primórdios da colonização, o cotidiano dos seridoenses e a organização de seu espaço. Nos sítios e nas fazendas de gado eram construídas capelas, o que gerava ou impulsionava práticas societárias. O desenvolvimento da povoação levava à construção de igrejas, por meio das quais eram estabelecidos arruamentos, dando origem a vilas e a cidades. Destarte, por meio do gado e da fé, foi sendo estabelecida certa vida urbana no Seridó Potiguar.

Outrossim, a delimitação histórica desse espaço ocorreu por meio das ações do Estado e da Igreja, considerando-se as instâncias religiosa e jurídica, pela criação de freguesias com comarcas. Assim, em 1748 foi criada a Freguesia da Senhora Sant'Ana, delineada de acordo com os limites do Rio Seridó e povoada por homens e sesmarias para criar gado. 
Essa Freguesia foi desmembrada da Freguesia de Nossa Senhora do Bom Sucesso do Piancó (localizada na Paraíba). Segundo Morais (2005, p. 70),

a vastidão do território da Freguesia de Nossa Senhora do Bom Sucesso, as dificuldades de locomoção, o crescimento da população e, por conseguinte, o aumento da demanda por serviços religiosos, foram fatores decisivos para o seu desmembramento, em 1748, dando origem à Freguesia da Gloriosa Senhora Sant'Anna do Seridó.

Pelo fato de ter sido criada pelo desmembramento da Freguesia de Nossa Senhora do Bom Sucesso do Piancó, o espaço da Freguesia da Gloriosa Senhora Sant'Ana do Seridó foi, durante décadas, disputado por autoridades potiguares e paraibanas. Essa disputa só foi resolvida em 1835, quando o governo imperial do Brasil - Primeiro Reinado (1822-1831), Segundo Reinado (1840-1889) - ratificou os limites da última como potiguares, levando em consideração a vontade do povo e de autoridades políticas do Seridó, as quais sempre encontraram maiores possibilidades de atuação na política norterio-grandense.

Com isso, historicamente, o espaço da Freguesia da Gloriosa Senhora Sant'Ana foi sendo desmembrado, dando origem a municípios e cidades do Seridó Potiguar (mapa 1). Segundo Morais (2005, p. 90), uma “cartografia estabelecida pela fé”, configurando a terra de Sant'Ana e, tradicionalmente, dos currais.

Do século XVII ao XIX, a atividade primaz da economia seridoense foi a pecuária. O criatório de gado era consorciado com o cultivo de gêneros alimentícios, que, em anos com boas chuvas, supria totalmente as necessidades alimentares dos seridoenses. Por meio do transporte e do comércio do gado havia intercâmbio com outros mercados. $O$ gado criado no Seridó era comprado, principalmente, no Piauí. No transporte do gado para o espaço seridoense, trazia-se farinha, rapadura e sal do Ceará. Após criado, o gado era tangido para Campina Grande (PB), onde seria comercializado. Assim, Macêdo ([2005] 2012, p. 83) esclarece que “[...] a interação do sertão com a sede política da Capitania e da Província do Rio Grande foi escassa na Colônia e no Império. A orientação econômica sertaneja dava-se pelo interior [...]". 
Macêdo ([2005] 2012) assevera que a identidade seridoense foi construída, historicamente, pelo discurso e pelas ações da elite regional. Sob a primazia da pecuária, o espaço foi significado, pela religião católica, como "espaço da provação e da promissão".

A pecuária tradicional do Seridó era atividade submetida ao fenômeno da seca, que afeta frequentemente o sertão. Destarte, a Freguesia do Seridó foi concedida a Sant'Ana, padroeira dos pastores, a quem se rogava dias melhores - nos momentos de seca - e se agradecia a graça alcançada - nos momentos de fartura.

As condições fisiográficas do Seridó causavam, mais do que hoje, fluxo e refluxo de gente e de gado. Nos momentos das frequentes e severas secas, muitos migravam em busca de trabalho e de água para sobreviverem. Quando vinham as chuvas, retornavam à sua terra para o desenvolvimento do criatório do gado e a conquista da vida pelo trabalho. Macêdo ([2005] 2012) afirma que o Seridó do gado submetia constantemente e intensivamente seu povo às provações da natureza, com as quais se convivia, na medida do possível, por meio de promessas a Sant'Ana.

Considerando o Seridó como espaço da provação e da promissão, as elites regionais comparavam os seridoenses a hebreus e egípcios, por serem povos do deserto, confiantes na ação divina. Morais (2005, p. 147) destaca a importância da religiosidade na formação do Seridó Potiguar quando diz que "a vivência dessa religiosidade refletia um forte grau de conformação à providência celestial, a quem se atribuía a abundância das chuvas ou os rigores da seca, portanto, tudo estava nas mãos de Deus". Nesse contexto, o homem seridoense era representado pela força para enfrentar adversidades e pela resistência às severas condições naturais do espaço.

O Seridó dos currais e da fé em Sant'Ana foi sustentado pela elite regional até os fins do século XIX. A partir de então, e durante a primeira metade do século XX, de acordo com princípios republicanos, construiu-se o discurso do "espaço da produção" fundamentado economicamente no desenvolvimento da cotonicultura e da mineração.

No Nordeste brasileiro, a cotonicultura foi impulsionada com a Guerra de Secessão, ou Guerra Civil, dos Estados Unidos da América (EUA) (1861-1865), quando esse 
país parou de abastecer a indústria têxtil inglesa. Tal abastecimento foi então conferido ao Nordeste do Brasil, fazendo com que pastos fossem substituídos por algodoais, tendose em vista maior rentabilidade e lucratividade obtida, respectivamente, por trabalhadores e detentores dos meios de produção.

No Seridó Potiguar, a cotonicultura ganhou realce após 1877 quando uma grande seca enfraqueceu severamente a pecuária. O Algodão Mocó - cultivado no Seridó abastecia, sobretudo, a nascente indústria têxtil brasileira, localizada, especificamente, em São Paulo. A fibra longa desse algodão agradava qualitativamente os industriais paulistas que o consideravam o melhor do Brasil.

Assim, do final do século XIX até a década de 1960, a cotonicultura foi a principal atividade econômica do Seridó e uma das principais do Rio Grande do Norte. Nas antigas fazendas de criar, passou-se a produzir algodão de modo intenso de forma complementar à pecuária pois o caroço do algodão servia de alimento para o gado.

O realce econômico do Seridó algodoeiro significou destaque da elite regional na política estadual. Lideranças seridoenses ligadas à cotonicultura foram eleitas para os cargos mais importantes do poder público potiguar, como o de governador do estado, conquistado por José Augusto Medeiros (mandato de 1924 a 1927), Juvenal Lamartine de Faria (1928-1930), Dinarte Mariz (1956-1961) e Walfredo Gurgel (1966-1971).

Morais (2005, p. 169-170) sublinha que a atividade de cultivo e transformação do algodão significou avanços importantes para a vida urbana no Seridó Potiguar, "[...] com a instalação de usinas de beneficiamento de algodão e de fábricas para industrialização de seus derivados. Algumas cidades passaram de meros entrepostos de comercialização a centros de beneficiamento do produto [...]". Outrossim, destaca a autora que

[...] o algodão foi fator decisivo para a dinamização e ampliação do setor terciário das cidades, principalmente dos centros regionais Caicó e Currais Novos, para o incremento das feiras semanais e para as melhorias em termos de infra-estrutura urbana. Neste aspecto destaca-se a instalação de instituições públicas e privadas para fins de prestação de serviços à comunidade; construção e asfaltamento de estradas como forma de interligar as áreas produtoras e facilitar o escoamento da produção; instalação do sistema de telefonia fundamental à articulação 
com o mercado consumidor e implantação de órgãos de pesquisa dedicados a estudos e experimentos relativos ao algodão, principalmente (MORAIS, 2005, p. 169-170).

Tendo em vista esses avanços, Macêdo ([2005] 2012) compreende que os governos seridoenses do território potiguar, sobretudo os ocorridos na República Velha (1889-1930), foram decisivos para a definição de investimentos em educação profissional, crédito e transporte (instalação de fixos para viabilizar fluxos), direcionados para a cotonicultura. Com isso, o espaço seridoense foi conectado de modo substancial ao da capital potiguar, estabelecendo-se fluxos frequentes de mercadorias, pessoas, capitais e informações entre o Seridó e o Litoral potiguares, via estrada de automóveis do Seridó, cuja construção e importância foi estudada por Silva (2015).

No contexto do Seridó cotonicultor, a elite regional algodoeiro-pecuarista não significou o espaço principalmente pela fé católica; a fé em Sant’Ana continuou a ser importante para o cotidiano dos seridoenses, contudo o Seridó passou a ser identificado por sua elite como espaço da "produção" do melhor algodão do Brasil, com uma das melhores fibras do mundo.

Enquanto a pecuária significou o início do Seridó e a fé dos seridoenses em Sant'Ana, a cotonicultura denotou o auge econômico e político do espaço, pelo fato de o algodão ser um produto destinado à exportação e ao realce da elite algodoeiropecuarista na política estadual. No entendimento de Macêdo ([2005] 2012, p. 199), o Seridó do "ouro branco" foi abstraído como espaço rico e desenvolvido, não obstante a falta de "facilidade" em sua natureza. Sob esse discurso, o seridoense foi comparado ao japonês: resistente e sóbrio diante de sua natureza madrasta. Sua região seria o espaço da "superação" de adversidades fisiográficas, por meio da "produção", sobretudo, algodoeira.

Todavia, nem só pelo algodão foi produzido o Seridó do “progresso econômico"; a atividade mineradora também foi importante para o auge econômico do espaço, desenvolvida, mormente, entre as décadas de 1940 e 1970. 
A mineração, no Seridó Potiguar, foi destacada pela exploração de scheelita, mineral extraído com vistas à obtenção de tungstênio, que, por sua dureza e elevada densidade, é bastante útil em aplicações militares, como em projéteis penetrantes. No início da década de 1940, foram descobertos depósitos de scheelita no Seridó, especialmente em Currais Novos, com exploração bastante viável, devido à deflagração da II Guerra Mundial (1939-1945) e da Guerra Fria (1945-1991). Tais conflitos mundiais estimularam a exploração de minérios utilizados pela indústria bélica, impulsionando, assim, a exportação de scheelita na região (MORAIS, 2005).

Nesse contexto, o Rio Grande do Norte era o maior produtor nacional de scheelita, sendo Currais Novos o município com as maiores reservas. Com isso, a cidade desse município obteve considerável desenvolvimento no período de destaque da mineração seridoense, recebendo infraestruturas destinadas a atender o desencadeamento da economia mineradora, como banco, hotel, escolas, hospital.

Podemos asseverar que a mineração transformou Currais Novos no segundo principal centro urbano do Seridó Potiguar por concentrar demografia e funcionalidades não existentes com a mesma intensidade e o mesmo nível nas outras cidades da região, com exceção de Caicó.

Historicamente, Caicó foi constituída como a principal cidade seridoense. Conforme fatos narrados por Morais (2005) e Macêdo ([2005] 2012), no Brasil Colônia, em 1735, o Arraial do Acauã foi elevado à categoria de povoação, sendo denominado Povoado de Caicó. Em 1748, foi criada a Freguesia de Sant'Ana, instalada em 26 de julho, no citado povoado, pelo padre Francisco Alves Maia, cura da freguesia recém-criada. Devido ao fato de no povoado haver as seguintes características: coronel de cavalaria, capela e pelourinho e, por isso, ter sido escolhido para localizar a Matriz de Sant'Ana, definiu-se Caicó como sede da freguesia.

Em 1788, o Povoado de Caicó foi elevado à categoria de primeiro município-vila do Seridó, recebendo o nome de Vila Nova do Príncipe, em homenagem a D. João VI. Em 1868, já no Brasil Império, foi criada a primeira cidade seridoense, sede do município de Vila Nova do Príncipe, chamada, inicialmente, de Cidade do Príncipe. A criação dessa 
cidade ocorreu pelo fato de ela ser a sede do único município que se confundia com o território da Freguesia de Sant’Ana, como também por sediar a Comarca do Seridó.

Em 1890, com a Proclamação da República, providenciou-se a mudança do nome da principal cidade do Seridó, de Cidade do Príncipe - nome representativo do Período Imperial - para Cidade do Seridó, ressaltando a tradição indígena da formação do espaço e o importante rio da Freguesia de Sant'Ana. Contudo, segundo Macêdo ([2005] 2012), a nova denominação não foi aceita pela população local, e, no mesmo ano, oficializou-se a denominação da cidade por seu nome mais tradicional, "Caicó", homenageando-se, assim, a geografia física do espaço e seu povoamento por indígenas.

Na primeira metade do século XX, sendo o Rio Grande do Norte governado por autoridades seridoenses, políticas públicas foram direcionadas, de maneira substancial, para o Seridó Potiguar. Por seu destaque histórico, demográfico e funcional, Caicó concentrou a maioria dessas políticas, consolidando-se como principal centro urbano seridoense, constituído pela produção do espaço pelo binômio gado-algodão. Como já dissemos, Currais Novos se apresenta como a segunda principal cidade do Seridó, tendo sua centralidade funcional constituída, sobretudo, no período áureo da mineração.

Assim, o espaço seridoense foi formado pela pecuária e pela fé em Sant'Ana e conquistou força econômica e política no território potiguar por meio da cotonicultura e da mineração. Por isso, o gado, o algodão e a scheelita são produtos tradicionais do Seridó, e a fé católica é uma marca do cotidiano dos seridoenses, desde a colonização do espaço.

\section{Crise das economias tradicionais e reestruturação econômica do Seridó} Potiguar

Na década de 1970, as economias tradicionais entraram em decadência, algumas chegando a falir. A cotonicultura foi afetada duramente pelo cultivo de algodão no Sudeste do país com maior competividade, o desenvolvimento de tecidos sintéticos em âmbito mundial, a praga do bicudo - que passou a destruir algodoais no Nordeste 
brasileiro - e a baixa produtividade e rentabilidade da produção algodoeira do Seridó, se comparada à ocorrida no Sudeste do Brasil e em outras regiões internacionais. Assim, a cotonicultura seridoense ruiu, praticamente desaparecendo.

A mineração não foi capaz de competir com a exploração de scheelita pelos chineses, muito mais competitiva que a desencadeada no Seridó Potiguar. Com isso, a China passou a atender, em larga escala, as demandas minerais da indústria bélica mundial, enfraquecendo severamente a mineração seridoense. Ao mesmo tempo, a pecuária continua, até hoje, a ser impactada negativamente pelos efeitos das secas periódicas que caracterizam a fisiografia seridoense, não se constituindo em atividade econômica nevrálgica para a atual dinâmica econômica da região.

Diante desse contexto de falência ou enfraquecimento das economias tradicionais do Seridó, a dinâmica regional foi reestruturada tendo como alicerce a urbanização. Com a crise constante da pecuária e a falência da cotonicultura, entre as décadas de 1970 e 1990 ocorreu forte migração campo-cidade nos municípios seridoenses e, hoje, a maior parte da população vive nas cidades.

Dados estatísticos do IBGE (2017) mostram que, assim como a do Brasil e a do Rio Grande do Norte, a população total do Seridó Potiguar cresceu entre 1970 e 2010. Esse crescimento foi impulsionado pelo aumento ininterrupto da população urbana. No Rio Grande do Norte e, especificamente, no Seridó Potiguar, em 1970, a população rural era maior do que a urbana. Contudo, já em 1980, em ambos os espaços, a população urbana tinha superado a rural. Em 2010, a grande maioria da população potiguar e seridoense era urbana: as taxas de urbanização eram de $77,8 \%$ e de $77,6 \%$, respectivamente. No Brasil, a taxa de urbanização, em 2010, foi de 84,4\%, ou seja, superior a do Rio Grande do Norte e a do Seridó Potiguar.

A dinâmica de cidades seridoenses vem sendo impulsionada pelos investimentos em infraestrutura e em serviços realizados pelo poder público e também pelos empregos por ele gerados. Contudo, essa dinâmica é diferente a depender do tamanho demográfico e da complexidade funcional dos centros urbanos. 
Em 2010, a maioria dos municípios do Seridó Potiguar tinha menos de 10.000 habitantes. Havia seis municípios que tinham população inferior a 6.000 habitantes. Nesses municípios minúsculos, houve, entre 1970 e 2010, pouca mudança no tamanho da população, com situações de pouco crescimento da demografia - caso de Ipueira e Equador -, de certa estagnação do tamanho da população - caso de Serra Negra do Norte - e também de redução da pequena população - caso de Florânia e Ouro Branco. Em três deles - Cerro Corá, Lagoa Nova e Tenente Laurentino Cruz -, em 2010 a população rural superava a urbana. Em Tenente Laurentino Cruz, 78,7\% da população vivia na zona rural. Esses dados indicam frágeis dinâmicas urbanas desses municípios.

Em 2010, apenas três municípios do Seridó Potiguar tinham mais de 20.000 habitantes - Parelhas, Currais Novos e Caicó. No que se refere à população urbana, apenas duas cidades ultrapassavam o contingente de 30.000 pessoas - Currais Novos e Caicó -, sendo esta a maior urbe seridoense, em termos demográficos e funcionais, com 57.461 moradores, no referido ano.

O destaque de Currais Novos e Caicó deve-se, bastante, à localização dos serviços da administração pública com maior nível de complexidade, fato que atrai, frequentemente, moradores de pequenas cidades em busca de serviços não existentes em outros locais. Do mesmo modo, Currais Novos e Caicó têm os mercados mais complexos do Seridó, possibilitando mercadorias e prestação de serviços não existentes nas outras cidades da região.

Outrossim, no que tange à condição de atividade da população, entre 1991 e 2010, no Brasil e no Seridó Potiguar, a maioria da população de 10 anos ou mais de idade era de pessoas economicamente ativas. No Rio Grande do Norte, em 1991 e 2000, a maioria eram pessoas não economicamente ativas; em 2010, no estado, o número de pessoas economicamente ativas superou o de pessoas não economicamente ativas.

No que diz respeito ao processo de urbanização, em toda a série histórica entre 1991 e 2000, tanto no Brasil quanto no Rio Grande do Norte e, particularmente, no Seridó Potiguar, a maioria das pessoas economicamente ativas e também das não economicamente ativas vivia em cidades. Outrossim, no Seridó Potiguar, houve 
diminuição do número de pessoas economicamente ativas e do de pessoas não economicamente ativas residentes no campo. Em contrapartida, também no espaço seridoense, tais números apresentaram constante aumento no que se refere ao espaço urbano.

Todavia, na dinâmica regional em questão, há municípios que apresentaram, em toda a série histórica em tela, população economicamente não ativa maior do que a economicamente ativa, a saber: Jucurutu, Lagoa Nova, Ouro Branco, São Fernando e Serra Negra do Norte. Tais municípios apresentam frágil mercado de trabalho, com o desenvolvimento de atividades econômicas destinadas, sobretudo, ao atendimento das necessidades vitais mínimas da população local e com características organizacionais e de níveis de tecnologia e de capital pouco complexas. Essa fragilidade do mercado pode explicar o fato de a maioria das pessoas com 10 ou mais anos de idade, residentes nos referidos municípios, não ser de população economicamente ativa entre 1991-2010.

Além disso, em alguns municípios, como Lagoa Nova - entre 1991 e 2000 -, São Fernando - em 1991 -, Serra Negra do Norte - entre 1991 e 2000 - e Tenente Laurentino Cruz - entre 2000 e 2010 -, a maioria da população economicamente ativa vivia no campo e não na cidade, fato que indica a fragilidade da dinâmica urbana desses municípios no que se refere a mercado, estrutura e processo de urbanização.

Não obstante a crise, ou mesmo falência das economias tradicionais, na segunda metade do século XX, sobretudo na virada para o século XXI, a economia do Seridó Potiguar foi pujante, muito alicerçada no desenvolvimento de atividades econômicas que têm como fundamento uma característica peculiar do Seridó no território do Rio Grande do Norte: a identidade regional. Segundo Morais (2005), essa identidade apresenta-se como importante fundamento da reestruturação econômica da região chegando a ser até mais importante do que certos nexos da Globalização.

Entre 1999 e 2014, na totalidade dos municípios do Seridó Potiguar, no Rio Grande do Norte e no Brasil, o crescimento do Produto Interno Bruto (PIB) foi constante, sendo que, entre 2005 e 2012, tal crescimento foi forte, conforme a conjuntura socioeconômica e política favorável do país. Esses dados indicam substancial crescimento econômico dos 
espaços em questão, sobretudo no período dos governos Lula (2003-2010) e no início dos governos Dilma (2011-2016), quando a economia do país foi dinamizada, em termos gerais, pelo incentivo ao consumo e por investimentos públicos em educação tecnológica e superior e em programas de transferência de renda. Essa dinamização rebateu positivamente no crescimento da economia potiguar, especificamente no da seridoense.

No tocante à participação percentual de ramos econômicos no valor total do PIB, entre 1999 e 2014, tanto no Brasil quanto no Rio Grande do Norte e no Seridó Potiguar, a participação do ramo da agropecuária na geração do PIB diminuiu, apesar de haver municípios seridoenses em que essa diminuição não foi confirmada, a saber: Acari, Equador, Florânia, Jardim do Seridó, São José do Seridó, São Vicente e Timbaúba dos Batistas.

A participação da indústria na geração do PIB do Seridó Potiguar teve leve incremento, enquanto que na totalidade do território potiguar e no Brasil teve leve diminuição, entre 1999 e 2014. Dentre os municípios seridoenses, destacam-se por terem interessante dinâmica produtiva os seguintes: Jardim de Piranhas - destaque para a produção de mercadorias do ramo têxtil; Lagoa Nova - produção de polpa de caju e de energia eólica; Parelhas - produção de cerâmicas vermelhas; Santana do Seridó produção de queijo e de vestimentas; e São José do Seridó - produção de vestimentas.

Vale destacar aqui o dado errado da participação da indústria no PIB de Cruzeta, em 2014, indicada como sendo de 70,79\%. Tal dado discrepa da realidade da dinâmica econômica cruzetense por não existirem unidades produtivas em quantidade e com qualidade que justifiquem esse percentual. Acreditamos que o percentual de 70,79\% seja, verdadeiramente, da participação das atividades comerciais e de serviços na geração do PIB cruzetense e que o percentual de $27,06 \%$ seja referente ao ramo industrial. Parece-nos que esses dados estão publicados erroneamente no site do IBGE.

No Brasil e em todo o território potiguar, as atividades comerciais e as de prestação de serviços são as que mais dinamizam o PIB, sendo que no país e no estado, entre 1999 e 2014, essa dinamização foi incrementada. No Seridó Potiguar, a participação dessas atividades no PIB foi um pouco diminuída na série histórica analisada, registrando- 
se o erro de publicação dos dados da participação da indústria e das atividades comerciais e de prestação de serviços na geração do PIB do município de Cruzeta, no ano de 2014.

Outrossim, quanto aos segmentos econômicos que mais ocupavam trabalhadores, em 2000, no Rio Grande do Norte, a maioria dos trabalhadores desempenhava, respectivamente, atividades comerciais e/ou de prestação de serviços, seguida pelos trabalhadores do ramo agropecuário e pelos do ramo produtivo. No Seridó Potiguar, a maioria trabalhava em atividades produtivas, em atividades comerciais e/ou de serviços ou em atividades agropecuárias. No Brasil, a maioria trabalhava em comércio e/ou na prestação de serviços, seguida pelos trabalhadores da produção e pelos que desenvolviam atividades agropecuárias.

Ainda em 2000, no Rio Grande do Norte e no Seridó Potiguar, a maioria dos trabalhadores havia estudado de 4 a 7 anos, de 1 a 3 anos ou de 11 a 14 anos, sendo que muitos trabalhadores não tinham instrução ou haviam estudado menos de um ano 12.795 trabalhadores no Seridó e 118.563 no Rio Grande do Norte, no total de 97.646 e 911.958 trabalhadores, respectivamente. No Brasil, a maioria dos trabalhadores havia estudado de 4 a 7 anos, de 11 a 14 anos ou de 8 a 10 anos. Eram trabalhadores que, no Seridó, obtinham rendimento médio mensal de R\$ 268,52; no Rio Grande do Norte, de R\$ 428,67; e, no Brasil, de $\mathrm{R} \$ 638,45$.

Em 2010, no Seridó Potiguar, os segmentos econômicos que mais ocupavam trabalhadores eram, respectivamente: os dos trabalhadores dos serviços, dos vendedores dos comércios e mercados; das ocupações elementares ${ }^{1}$; dos trabalhadores qualificados da agropecuária, florestais, da caça e da pesca; dos trabalhadores qualificados, operários e artesãos da construção, das artes mecânicas e outros ofícios; e dos operadores de instalações e máquinas e montadores. No Rio Grande do Norte e no Brasil, destacaram-se os segmentos das ocupações elementares e dos trabalhadores dos serviços, vendedores dos comércios e mercados, nessa ordem.

\footnotetext{
${ }^{1}$ Ocupações elementares são aquelas que não requerem alto nível de qualificação ou de competências e habilidades para serem desenvolvidas. São ocupações básicas, simples. Exemplos: trabalhadores domésticos, ajudantes de cozinha, pessoal de limpeza, vendedores ambulantes, coletores de lenha, mensageiros de hotel, carregadores de bagagem (IBGE, 2010).
} 
No Seridó Potiguar, no Rio Grande do Norte e no Brasil, em 2010, a maioria dos trabalhadores não tinha instrução ou não havia completado o Ensino Fundamental. Eram trabalhadores que obtinham, respectivamente, rendimentos médios mensais de $\mathrm{R} \$$ 616,95, R\$ 982,68 e R\$ 1.340,48. Na série histórica de 2000 a 2010, tanto na região quanto no estado e no país, de modo geral, as trabalhadoras estudavam mais, porém conseguiam rendimentos menores que os dos homens.

Além disso, também entre 2000 e 2010, no Brasil, no Rio Grande do Norte e no Seridó, aumentou o número de trabalhadores designados pelo Instituto Brasileiro de Geografia e Estatística (IBGE) como “empregados". Contudo, no estado e no Seridó, em toda a série histórica, a maioria dos trabalhadores era de "empregados sem registro em carteira de trabalho" ou de trabalhadores "por conta própria", os quais, segundo literatura acadêmica (SINGER, 1996), não são empregados, mas sim ocupados². No Brasil, apenas em 2010, o total desses trabalhadores foi menor que o de trabalhadores “verdadeiramente empregados", isto é, com registro em carteira de trabalho.

Tais dados estatísticos mostram que, desde a segunda metade do século XX, no que tange ao Seridó Potiguar, a dinâmica regional vem ocorrendo bastante atrelada às dinâmicas de cidades, com destaque para os centros urbanos com maior funcionalidade e demografia. Assim, seguindo o processo nacional de urbanização, a economia seridoense vem sendo reestruturada, sublinhando-se, de modo genérico, atividades comerciais e de serviços mas, também, em determinadas situações geográficas, atividades produtivas concernentes a ramos específicos, como o têxtil, o da construção civil e o da energia eólica. O processo de mudança da tradicional estrutura econômica mantém a maioria dos trabalhadores em situações de vida e de trabalho precárias por ofertar poucas possibilidades de estudo, de capacitação e rendimentos mensais ínfimos, abaixo das médias estadual e nacional.

\footnotetext{
${ }^{2}$ Singer (1996) esclarece que ocupação é toda forma de atividade que proporciona renda e possibilidade de consumo a quem a exerce, sem que haja, necessariamente, assalariamento do trabalhador e garantia de direitos trabalhistas. Além disso, a ocupação pode ser por conta própria, não havendo relação entre patrão e trabalhador. Emprego é um tipo de ocupação que, sem flexibilizações, deveria implicar assalariamento e garantia de direitos sociais ao trabalhador empregado. Outrossim, o emprego é sempre uma relação de trabalho, na qual a um empregador se vincula empregado.
} 
Neste contexto, um aspecto particulariza o Seridó Potiguar e orgulha os seridoenses: o da identidade regional. Ela se constitui como uma marca, que é significada pelo fazer com qualidade e com arte: os alimentos e as vestimentas produzidas na região são reconhecidos por sua qualidade diferenciada, muitas vezes constituindo-se de peças de artesanato (no sentido de artístico) feitas com o maior zelo possível. Por isso ocupam lugar de destaque nos principais mercados potiguares.

Do mesmo modo, o povo seridoense é reconhecido como diferenciado, por sua força e resistência às adversidades fisiográficas, políticas e econômicas, como também por sua receptividade. Assim, a nova dinâmica do Seridó é marcada por festas religiosas e profanas que atraem muitos turistas para as cidades da região. Na principal delas, Caicó, destacam-se o Carnaval e a Festa de Sant'Ana, momentos nos quais tem sua dinâmica demográfica, produtiva e comercial bastante amplificada.

A fé em Sant'Ana é, hoje, mais do que um traço da cultura seridoense; é uma possibilidade de aquecimento da dinâmica do espaço, especificamente no que se refere à cidade de Caicó, considerada “Terra de Sant’Ana” e "Capital do Seridó”. Nesses termos, Morais (2005) enfatiza a "força social do Seridó", tendo em vista o realce que é dado à tradição cultural do espaço no processo de reestruturação da dinâmica urbano-regional.

\section{Considerações finais}

A história da formação e da produção do espaço do Seridó Potiguar traz à baila a construção de uma região, na qual a identidade do povo é singular, no contexto do Rio Grande do Norte, por ser bastante alicerçada na fé em Sant'Ana. Desde a colonização do espaço até o momento atual, a fé na Senhora Sant'Ana sempre caracterizou a vida dos seridoenses e, portanto, a dinâmica do espaço produzido por eles. Outrora, com destaque da pecuária, o seridoense era identificado como homem forte, resistente às dificuldades que a natureza de seu espaço lhe impõe e, assim, o Seridó era representado como espaço da provação - diante da seca - e da promissão a Sant'Ana, padroeira dos pastores, a quem se rogava - e continua-se a rogar - por dias melhores, com abundância. 
O período áureo da região ocorreu quando o "ouro branco" cultivado em suas terras interessou ao mercado internacional e, sobretudo, à nascente indústria têxtil paulista. Abastecendo essa indústria com o Algodão Mocó, seridoenses ganharam realce na economia e na política do Rio Grande do Norte, transformando sua região em espaço da produção - em quantidade e com qualidade -, não obstante as dificuldades enfrentadas na relação com a árida natureza do sertão do Seridó.

Outrossim, no contexto da II Guerra Mundial e da Guerra Fria, a scheelita interessou ao mercado internacional como matéria-prima da indústria bélica. Por ser mineral abundante em terras seridoenses, a economia proveniente de sua exploração também contribuiu para o realce do Seridó Potiguar no contexto da dinâmica estadual, sobretudo no que se refere à infraestrutura e à vida urbana implementadas em Currais Novos, tornada, assim, a segunda cidade mais importante da região, em termos demográfico e funcional.

De maneira geral, na primeira metade do século XX, a Região do Seridó Potiguar ganhou holofotes na economia e na política do Rio Grande do Norte, por estar fundamentada nas divisas provenientes de duas economias atrativas a mercados exógenos: a cotonicultura e a mineração.

Todavia, na segunda metade do século XX, tal situação foi alterada, devido à crise e falência da cotonicultura e da mineração desenvolvidas na região, motivadas por fatores conjunturais - referentes ao mercado internacional - e estruturais - concernentes à baixa complexidade dos processos produtivos desencadeados, tornando-os pouco competitivos frente a outros circuitos produtivos.

Nesse cenário, das economias tradicionais, restou apenas a pecuária, desenvolvida de modo pouco moderno e bastante sujeita às adversidades da seca. Sendo assim, sozinha, a pecuária não foi capaz de dinamizar amplificadamente a economia, a sociedade e a política da região. Destarte, buscou-se a reestruturação da economia seridoense, encontrada, sobretudo, a partir da década de 1970, na urbanização, alicerçada no desencadeamento de pequenas atividades comerciais e de prestação de serviços. Nas cidades de maior demografia, a prestação de serviços é mais complexa - devido à maior 
presença da administração pública - assim como o mercado do comércio é maior, quantitativa e qualitativamente.

Nas pequenas cidades seridoenses, além da existência de atividades comerciais e de serviços, o poder público vem dinamizando a economia por meio do apoio a capitais produtivos. Com esse apoio público, agentes e/ou empresas privadas vêm produzindo cerâmicas vermelhas, vestimentas e alimentos, que são distribuídos para variados mercados externos, gerando, assim, ocupações e empregos que sustentam várias famílias. Outrossim, empresas vêm instalando parques eólicos em pequenos municípios do Seridó, gerando e distribuindo energia eólica e proporcionando o pagamento de royalties ao poder público.

É fato que a atual dinâmica urbano-regional do Seridó segue a perspectiva nacional de destaque das atividades comerciais e de prestação de serviços na participação do PIB bem como dos investimentos produtivos por intermédio de parcerias entre os setores público e privado. Contudo, no Seridó Potiguar, a perspectiva econômica tem um tempero particular que é a identidade regional.

Geralmente, a tradição do sertão do Seridó marca as atividades comerciais, de serviços e produtivas desenvolvidas na região. O produto seridoense é reconhecido no Rio Grande do Norte como sendo diferente, por sua qualidade. Do mesmo modo, o povo seridoense, extremamente identificado com sua terra, é também destacado por sua fé, sua alegria e sua receptividade, explicitadas em dois eventos que aquecem a economia, sobretudo a da maior cidade da região: o Carnaval e a Festa de Sant’Ana, em Caicó.

Destarte, uma agenda de estudos geográficos está aberta acerca de uma importante região do território potiguar, fazendo-se necessário que a ciência geográfica pensada no âmbito desse território atente para a economia urbana de circuitos espaciais produtivos que dinamizam o urbano-regional em questão, sem negligenciar o importante fundamento da identidade regional. 


\section{Referências}

ALBUQUERQUE JÚNIOR, Durval Muniz de. O engenho antimoderno: a invenção do Nordeste e outras artes. 1994. Tese (Doutorado em História) - Universidade Estadual de Campinas, Campinas, 1994.

CASTRO, Iná Elias de. 0 mito da necessidade: discurso e prática do regionalismo nordestino. Rio de Janeiro: Bertrand Brasil, 1992.

IBGE - INSTITUTO BRASILEIRO DE GEOGRAFIA E ESTATÍ́STICA. Classificação de ocupações para pesquisas domiciliares - COD. In: $8^{\circ}$ FÓRUM SIPD. Rio de Janeiro: IBGE, o9 de julho de 2010. Disponível em: https://ww2.ibge.gov.br/home/estatistica/indicadores/sipd/oit avo forum/COD.pdf. Acesso em: 25 de jan. de 2019.

IBGE - INSTITUTO BRASILEIRO DE GEOGRAFIA E ESTATÍSTICA. Sistema IBGE de recuperação automática - SIDRA: território. Rio de Janeiro: IBGE, 2017. Disponível em: https://sidra.ibge.gov.br/territorio. Acesso em: 25 maio 2017.

MACÊDO, Muirakytan Kennedy de. Os seridoenses. Revista Caicó em Foco, Caicó (RN), v. 01, p. 05, 2000.

MACÊDO, Muirakytan Kennedy de. A penúltima versão do Seridó: uma história do regionalismo seridoense. 2. ed. Natal: EDUFRN, [2005] 2012.

MORAIS, Ione Rodrigues Diniz. Seridó Norte-Rio-Grandense: uma geografia da resistência. Caicó: Edição do Autor, 2005.

SANTOS, Milton. Espaço e sociedade: ensaios. Petrópolis: Vozes, 1979.

SILVA, Fagner David da. A estrada de automóveis do Seridó e a constituição de uma nova mobilidade no território norte-rio-grandense (1914-1934). Revista de História da UEG, Morrinhos (GO), v. 4, n. 2, p. 189-210, ago./dez. 2015.

SINGER, Paul. Desemprego e exclusão social. São Paulo em Perspectiva, São Paulo (SP), v. 10, n. 1, p. 03-12, jan./mar. 1996. 
Recebido em: 14/02/2019 Aprovado em: 27/06/2019

Universidade do Estado de Santa Catarina - UDESC

Centro de Ciências Humanas e da Educação - FAED

Revista PerCursos

Volume 20 - Número 43 - Ano 2019 revistapercursos@gmail.com 